\title{
Comparison of the Effects of Using Traditional Thai Musical Instruments and Carl Orff's Instruments on Mentally Disabled Children's Perception and Reaction to the Musical Elements
}

\section{Tepika Rodsakan}

Department of Music Education, Faculty of Fine Arts, Srinakharinwirot University, Bangkok, Thailand.

\begin{abstract}
This research dealt with the comparison of the effects of using traditional Thai musical instruments and Carl Orff's instruments on mentally disabled children's perception and reaction to the musical elements. The objectives of the research were 1) to study the results of the effects of using traditional Thai musical instruments on mentally disabled children's perception and reaction to the musical elements 2) to study the results of the effects of Carl Orff's instruments on mentally disabled children's perception and reaction to the musical elements 3) to compare the results of the effects of using traditional Thai musical instruments and Carl Orff's instruments on mentally disabled children's perception and reaction to the musical elements. The sample used in the research were 11 educable mentally disabled children from Panyawutikorn School aged between 8-10 years old. The sample had been tested and confirmed by the psychologist to have IQ range from 50-70, to be non-sound sensitive and to be devoid of any multiple handicaps. The sample were selected using purposive sampling. The tool used in this research were an interactive 9-question test of the sample group's perception and reaction to musical elements using traditional Thai musical instruments and Carl Orff's instruments. The sample group responded accordingly to the different given tasks in the test including singing, physical movement, playing musical instruments and musically melodic creation. The data obtained are then analyzed using statistical calculation, i.e. median, percentage and mean. The test results revealed the following findings; the results were as follows:

1. Results of the effects of using traditional Thai musical instruments on mentally disabled children's perception and reaction to the musical elements were found to be in the "good" criteria.

2. Results of the effects of using Carl Orff's instruments on mentally disabled children's perception and reaction to the musical elements were found to be in the "good" criteria. When considered each factor individually, the perception and reaction to sound was in the "fair" criteria while the perception and reaction to rhythm and melody were in the "good" criteria.

3. By comparing the results of the effect of using traditional Thai musical instruments and Carl Orff's instruments on mentally disabled children's perception and reaction to the musical elements, it was found to be different on the whole. When considered each factor individually, there was a difference in the perception of sound while there was no difference in perception and reaction to rhythm and melody.
\end{abstract}

Keywords: traditional thai musical instruments, Carl Orff's instruments, mentally disabled children, perception and reaction, and musical elements 


\section{INTRODUCTION}

Music Therapy is a science of implementing music and its elements to bring about a change, development or maintenance of physical, mental and social wellbeing. A music therapist systematically carries out various well-defined, scientific musical activities which lead to determined objectives. The goal of music therapy does not emphasize on mere musical skill, but a holistic development of physical, mental and social aspects according to each patient's needs. Music therapy can be cross-applied in educational and medical field, to name a few. Music Therapy has in itself many distinctive characteristics (Tweesak Sirirat-rekha. 2553: online) suitable for both normal and handicapped. One of the key elements of music therapy is musical instruments.

Musical instruments is such a significant tool that can draw a patient's attention towards the therapy without knowing that one is being treated. Currently, the musical instruments used for treating the handicapped are imported from foreign countries of the Western hemisphere including Carl Orff's instruments. Moreover, the researcher has also found that the application of traditional Thai musical knowledge and instruments for the purpose of music therapy is very much limited, though, considering its suitability for Thai people lifestyle and culture. Traditional Thai musical instruments, like other musical instruments, could be fitting for treating Thai patients. Busakorn Samrongthong and group (2544:1) cited that the study of possibility of using traditional Thai musical instruments as a tool for music therapy is an interesting topic and should be seriously researched. The obtained results can be beneficial in treating Thai patients as Thai people are more familiar to their own musical experiences and instruments. On top of that, Thai musical repertoires are often rearranged as LOOK THOONG and LOOK KRUNG songs whose lyrics are widely understood by the people of all ages and genders, including handicapped and children with mental disability.

The mentally disabled children, however, have a slower development rate compared to that of normal children. When tested with standard intellectual test, it is found that their intelligent quotient (IQ) are below average. Their abilities to adjust themselves are also limited. Their behavioral adjustment skills are below average by at least 2 fields of skills or more, such as communication skills, social skills, skills dealing with using public property, self-caretaking skills, inhouse living skills, self-control skills and learning skills. Mental disability can be classified in to 4 categories which are 1) mild disability, IQ 50-70 2) moderate disability, IQ 35-55 3) severe disability, IQ 20-40 4) extremely severe disability, IQ 20-25 (Alternative Medicine Bureau. 2551 : 68-69). Due to this, a therapist has to carefully consider selection of suitable musical instruments for a child so that the best outcome can be reached. At present, however, there has been no serious study regarding the comparisons of the results of perception and reaction after using traditional Thai musical instruments against Carl Orff's musical instruments. There are, however, few researches on comparison of the effects of using traditional Thai musical instruments and foreign musical instruments on 
mentally disabled children's. The results of these research can be very useful in planning a therapy program for mentally disabled children.

With the current situation and its significant mentioned, the researcher was inspiringly driven to conduct a research entitled "Comparison of the effects of using traditional Thai musical instruments and Carl Orff's instruments on mentally disabled children's perception and reaction to the musical elements". The research can be useful to any concerned individuals in planning a supportive program for mentally disabled children's development so they can adjust and prepare to live a happy life with everyone around them.

\section{RESEARCH OBJECTIVES}

1. to study the results of the effects of using traditional Thai musical instruments on mentally disabled children's perception and reaction to the musical elements

2. to study the results of the effects of Carl Orff's instruments on mentally disabled children's perception and reaction to the musical elements

3. to compare the results of the effects of using traditional Thai musical instruments and Carl Orff's instruments on mentally disabled children's perception and reaction to the musical elements

\section{MATERIALS AND METHODS}

Population and Sample Group Scope

Population

Population used in the research were mentally disabled children whose Intelligence Quotient score lie in between 50-70

\section{Sample Group}

The sample used in the research was 11 educable, mentally disabled children from Panyawutikorn School, Bangkok, Thailand, aged between 8-10 years old. The sample had been tested and confirmed by the psychologist to have IQ from 50-70, to be non-sound sensitive and to be devoid of multiple handicaps.

The tools for collecting data for this research was a test on mentally disabled children's perception reaction to musical elements (The researcher determined particular issues for testing the integrated musical instruments concerning the perception and reaction to musical elements, i.e. rhythm, melody and sound by implementing various musical skills such, i.e. listening, singing, physical movement, playing musical instruments, musical creation and interpretation of musical signs. The children would in turn indicate their perception and reaction through clapping, tapping, singing, dancing along music, patterned or free physical movement, patterned musical instruments execution and other means of creative thoughts regarding music and expression.) by using traditional Thai musical instruments and Carl Orff's instruments which were invented by the 
researcher. Data obtained were then analysed using statistics, which were median, percentage and mean. The test consisted of 9 tasks for testing the perception and reaction to sound, rhythm and melody which run in the following orders.

3 tasks of 15 points for perception and reaction to sound

3 tasks of 15 points for perception and reaction to rhythm

3 tasks of 15 points for perception and reaction to melody

The total score of the test was worth 45 points and was evaluated into 3 levels as follow:

$34.51-45.00$ points indicates good perception and reaction to musical elements. $24.51-34.50$ points indicates fair perception and reaction to musical elements. $0.00-24.50$ points indicates poor perception and reaction to musical elements.

The test was then inspected by 3 specialists, i.e. a special education experts and 2 musical experts for content validity, revised following the specialists' advises and then conducted as try-out with the mentally disabled children who are characteristically similar to the sample group to find out the test's reliability. Finally, the test was conducted to the sample group of mentally disabled children.

The invented test for perception and reaction to musical elements was introduced to the sample groups, i.e. 11 mentally disabled children using traditional Thai musical instruments and Carl Orff's instruments. The sample were divided in to 2 groups. The first group consisted of 5 children whereas the second consisted of 6 children. The first were tested with traditional Thai musical instruments and the second with Carl Orff's instruments. After completing the questionnaire, the groups interchanged the instruments and the procedure was then repeated. After the completion of the test, 2 sets of data obtained from using Thai musical instruments and Carl Orff's instruments was then analyzed, compared and concluded into a complete published research.

Statistics Used for data analysis.

1. Median

2. Percentage

3. Mean

\section{DISCUSSION}

By comparing the effects of using traditional Thai Musical instruments and Carl Orff's instruments on mentally disabled children's perception and reaction to the musical elements, the results can be concluded as follows.

By comparing the results of the effect of using traditional Thai musical instruments and Carl Orff's instruments on mentally disabled children's perception and reaction to the musical elements, it was found to be different on the whole. When considered each factor individually, there was a difference in the 
perception of sound while there was no difference in perception and reaction to rhythm and melody

\begin{tabular}{|c|c|c|c|}
\hline \multirow{2}{*}{ Music elements } & \multicolumn{2}{|c|}{ sample $(\mathrm{n}=11)$} & \multirow{2}{*}{$\begin{array}{l}\text { Effects on } \\
\text { perception and } \\
\text { reaction }\end{array}$} \\
\hline & $\begin{array}{l}\text { Thai musical } \\
\text { instruments }\end{array}$ & $\begin{array}{l}\text { Carl Orff's } \\
\text { instruments }\end{array}$ & \\
\hline $\begin{array}{l}\text { Perception and } \\
\text { reaction to sound } \\
\text { Perception and } \\
\text { reaction to rhythm } \\
\text { Perception and } \\
\text { reaction to melody }\end{array}$ & $\begin{array}{l}13.54 \\
12.81 \\
11.63\end{array}$ & $\begin{array}{l}8.45 \\
12.81 \\
11.09\end{array}$ & $\begin{array}{l}5.09 \\
0 \\
0.54\end{array}$ \\
\hline Total & 37.98 & 32.35 & 5.63 \\
\hline
\end{tabular}

Form the table of Aggregate element-wise comparison table of the effects of using traditional Thai musical instruments and Carl Orff's instruments on mentally disabled children's perception and reaction to the musical elements.

\section{CONCLUSION}

From the comparison of the effects of using traditional Thai Musical instruments and Carl Orff's instruments on mentally disabled children's perception and reaction to the musical elements, the researcher can conclude that:

There was different effects of perception and reaction to musical elements between Traditional Thai musical instruments and Carl Orff's instruments. It was found that the perception and reaction to sound using traditional Thai musical instruments was in "good" criteria whereas the perception and reaction to sound using Carl Orff's instruments was in "fair" criteria. As the results suggest, traditional Thai musical instruments are most suitable selection for educable mentally disabled children's perception and reaction to sound. In terms of perception and reaction to rhythm and melody, there was no difference between the two results, which was found to be in the "good" criteria. Therefore, traditional Thai musical instruments and Carl Orff's instruments can both be chosen to develop educable mentally disabled children's perception and reaction to rhythm and melody. From the results, it could be implied that traditional Thai musical instruments could well be used as effective tools to enhance development of a mentally disabled children due to children's familiarity, its abundant availability and relatively low cost. 


\section{REFERENCES}

Samrongthong, Budsakorn and group. (2001). Final Research Report on Music Therapy Project: ThaiTraditional Music as a Means of Therapy using Akaboshi's Principles of Music Therapy. The Thailand Research Fund.49.

Thai Alternative Medicine Office. (2008). Music Therapy. Thai Alternative Medicine Office, Department of Thai medicine and Alternative Medicine Promotion, Ministry of Public Health of Thailand., 68-69.

\section{ONLINE RESOURCES}

Siriratrekha, Taweesak. ( 2010). Music Therapy. http://www.happyhomeclinic.com/ a06- musictherapy.htm,. August 10, 2010. 